\title{
periferio
}

\section{POLÍTICAS PÚBLICAS DE COMBATE E ENFRENTAMENTO À VIOLÊNCIA DE GÊNERO}

\author{
Rosane Cristina de Oliveira ${ }^{1}$ \\ Universidade do Grande Rio - Unigranrio \\ Elaine Cristina Tenório Cavalcanti ${ }^{2}$ \\ Universidade do Grande Rio - Unigranrio
}

\section{Resumo}

O presente artigo tem como objetivo promover uma discussão teórica sobre violência de gênero articulando-a com as questões das políticas públicas para o seu enfrentamento. Nesse sentido, buscamos apontar a necessidade de políticas públicas, consideradas necessárias para um enfrentamento responsável e duradouro da violência de gênero. Partimos do pressuposto de que a violência é inseparável da noção de gênero porque se baseia e é praticada na e pela diferença social entre mulheres e homens.

Palavras-chave: violência; gênero; políticas públicas

1 Doutora em Ciências Sociais pela Universidade do Estado do Rio de Janeiro (UERJ). Professora do Programa de Pós-Graduação em Humanidades, Culturas e Artes da Unigranrio. rosane_oliveira@unigranrio.br

${ }^{2}$ Advogada e Bacharel em Direito pela Universidade Federal Fluminense (UFF). Mestranda do Programa de Pós-Graduação em Humanidades, Culturas e Artes da Unigranrio. eliane.cavalcanti@hotmail.com 


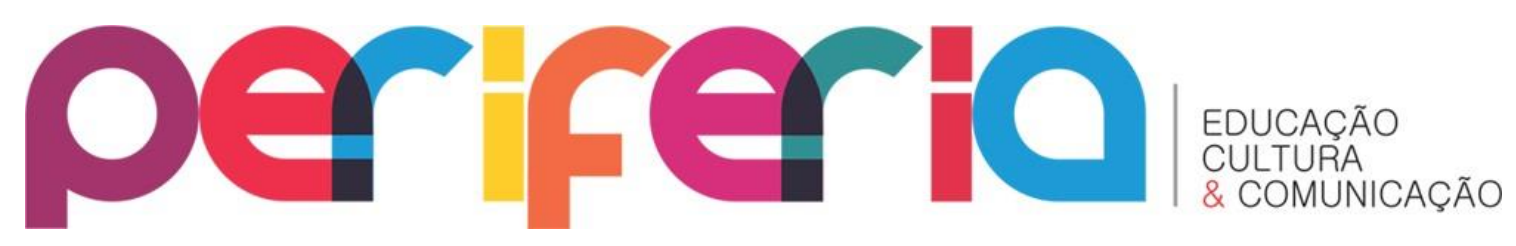

\title{
PUBLIC POLICIES TO COMBAT AND COPING GENDER VIOLENCE
}

\begin{abstract}
This article aims to promote a theoretical discussion about gender violence by articulating it with public policy issues to address it. In this sense, we seek to point out the need for public policies considered necessary for a responsible and enduring confrontation of gender violence. We start from the assumption that violence is inseparable from the notion of gender because it is based on and practiced in and by the social difference between women and men.
\end{abstract}

Keywords: violence; genre; public policy 


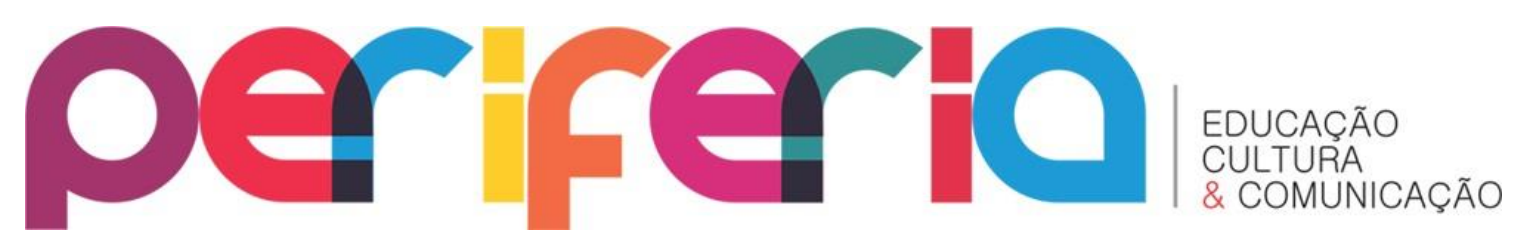

\section{INTRODUÇÃO}

A violência de gênero atinge mulheres no mundo inteiro e está assentada na tradição cultural, na organização social, nas estruturas econômicas e nas relações de poder. Essa forma de violência é praticada contra pessoa do sexo feminino, somente pela sua condição de mulher, a qual explicita as desigualdades socioculturais existentes entre homens e mulheres construídas ao longo da história, gerando uma relação pautada na desigualdade, na discriminação, na subordinação e no abuso de poder.

Segundo DAY et al (2003), em todo mundo, pelo menos uma em cada três mulheres sofreu espancamento ou algum tipo de abuso ao longo de sua vida e que $70 \%$ dos homicídios de mulheres foram praticados pelo cônjuge. Lamoglia e Minayo (2009) apontam que no Brasil, 29\% das mulheres relataram ter sofrido violência física de seus companheiros ao menos uma vez na vida, sendo que um quarto dessas mulheres compreendeu as agressões como violência grave, por terem sido chutadas, arrastadas pelo chão, ameaçadas ou feridas com armas.

Morgado (2004) afirma que a violência doméstica é a sexta causa de morte ou incapacidade física em mulheres na faixa etária entre 15 a 44 anos. Esses indicadores apresentam uma realidade bastante preocupante. É importante ressaltar que, apesar desses números já serem alarmantes, eles não abarcam o total dos casos, pois a maior parte episódios de violência não são denunciados.

De acordo com Tavares et al (2011) a violência de gênero é um problema social preocupante e, como tal, reivindica do Estado políticas públicas no sentido de prevenir e combater este tipo de violência.

Destarte, o presente artigo pretende realizar inicialmente uma discussão teórica sobre violência de gênero, a seguir, discorre-se acerca das políticas públicas de enfrentamento à violência de gênero, concluindo-se com as considerações finais do estudo. 


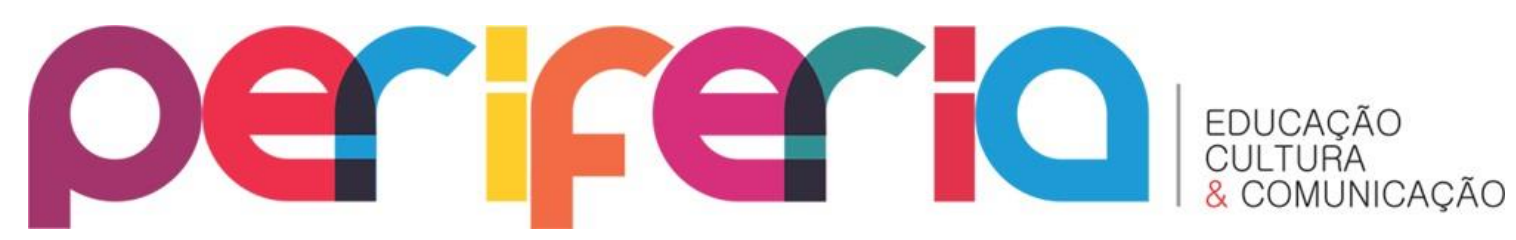

\section{A QUESTÃO DA VIOLÊNCIA DE GÊNERO}

De acordo com a OEA - Organização dos Estados Americanos - (1994) a violência contra a mulher representa ato ou conduta baseada no gênero, que cause morte, dano ou sofrimento físico, sexual ou psicológico à mulher, tanto na esfera pública como na esfera privada. Desse modo, conforme essa definição compreende-se a violência contra a mulher como um fenômeno relacionado ao gênero.

Como define Scott (1990, p.16) "o gênero é o primeiro campo no seio do qual, ou por meio do qual, o poder é articulado". A noção de gênero implica uma relação de poder imposta culturalmente a homens e mulheres. Neste sentido, os papéis destinados tanto para homens como para mulheres foram socialmente construídos e naturalizados, cabendo à mulher a obediência na infância ao pai e, mais tarde, ao companheiro, o que caracteriza uma ordem patriarcal de organização familiar.

Segundo Saffioti (2004) o patriarcado refere-se ao sistema social no qual o homem é o ator fundamental da organização social, utilizando da sua autoridade, o poder de macho, sobre as mulheres e os filhos. 0 patriarcado representa o regime da dominação-exploração das mulheres pelos homens.

De acordo com Koss (2000), essas mulheres ficam com a responsabilidade principal de cuidar das crianças e do trabalho doméstico, enquanto os homens nascem com a responsabilidade de sustentar a família. A preponderante divisão de trabalho entre os sexos levou homens e mulheres a assumir posições desiguais em termos de poder, prestígio e riqueza.

Desta forma, homens e mulheres ao longo dos anos ocuparam posições desiguais na sociedade. Esta desigualdade é resultante de uma construção social que determina, através da divisão sexual de papéis, os campos em que as mulheres podem agir e aqueles outros nos quais os homens podem atuar. Isto importa uma organização social de gênero que é amplamente hierarquizada e que contém em si a violência (KOSS, 2000). 


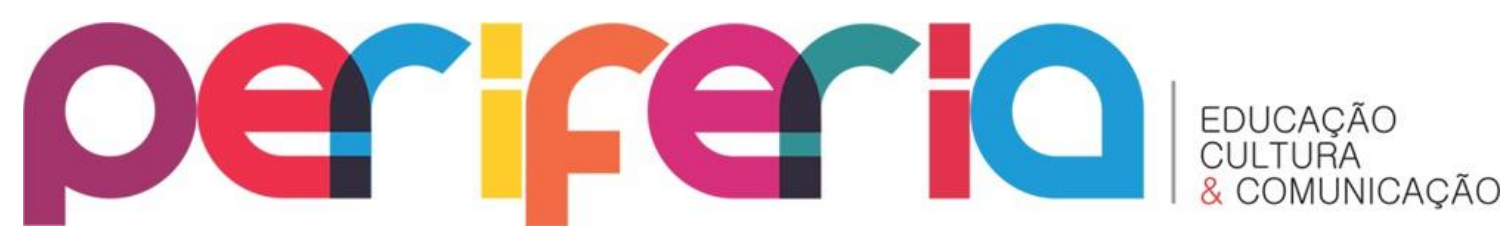

Segundo Saffioti (2004) a violência contra a mulher integra a organização social de gênero. As relações sociais são estabelecidas por esta organização social de gênero, sendo, portanto, relações criadas e construídas pelo próprio homem e não algo inato. Assim, é a sociedade que estabelece o que é ser homem e o ser mulher. Isso enfatiza o pensamento de Beauvoir (1980, p. 9), ao afirmar que “não se nasce mulher torna-se mulher”. Os indivíduos aprendem a internalizar os padrões de comportamento que são repassados de geração em geração.

Segundo Lisboa et al. (2009) o gênero refere-se a modelos cristalizados no homem e na mulher que foram produzidos como verdades na sociedade. Os papéis sociais, valores, normas e modelos produzidos e reproduzidos socialmente, ao longo do tempo, balizam a ação de mulheres e homens em sociedade. Assim, as atitudes autoritárias e centralizadoras dos homens são compreendidas como algo inerente à figura masculina e a subordinação a essa autoridade à figura feminina. Da necessidade de reforçar esse poder masculino, pode advir a violência contra a mulher.

Foucault (2001) afirma que a violência pode ser um instrumento utilizado nas relações de poder embora sejam fenômenos distintos, estão diretamente relacionados, e que a chave para a compreensão da violência é a forma como se concebe o poder. Assim, a violência surge como recurso ou alternativa para manter a estrutura de poder.

Segundo Fontana e Santos (2001), a violência contra a mulher encontra justificativa em normas sociais baseadas nas relações de gênero, ou seja, em regras que reforçam uma valorização diferenciada para os papéis masculinos e femininos. Desta forma, a violência de gênero se caracteriza pela recorrência e pela naturalização, fato este que dificulta a denúncia do agressor. Sagot (2007) afirma que no interior da família as desigualdades produzidas por gênero são mais evidentes e constituem as principais determinantes das relações violentas contra a mulher.

Saffioti (2004) afirma que a adoção da categoria de gênero implicou no reconhecimento de que as diferenças sexuais, mais do que biologicamente 


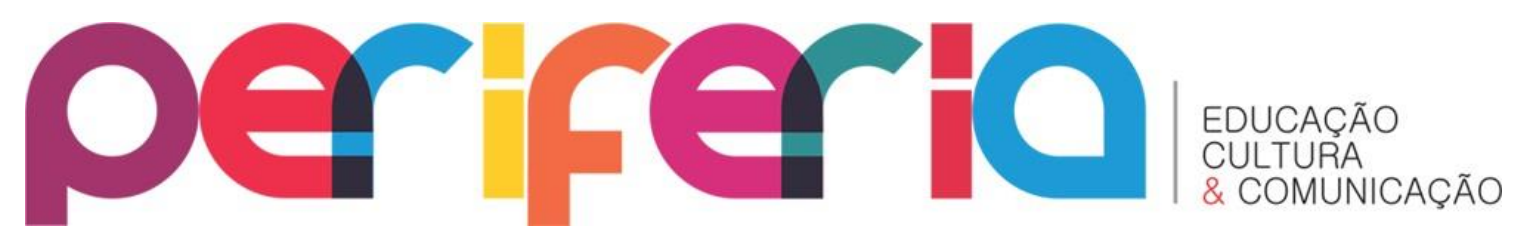

determinadas, são socialmente definidas, estando sujeitas a variações culturais na determinação dos papéis sociais de homens e mulheres.

De acordo com Grossi (1998) no Brasil, o termo gênero começou a ser utilizado no final dos anos 70 e rapidamente difundiu-se devido os movimentos feministas contra homicídios de mulheres e impunidade dos agressores, em geral, por seus próprios companheiros em nome da defesa da honra. No início dos anos 80 esses movimentos se estenderam para a denúncia de agressões e maus tratos conjugais. Com isso o termo passou a ser usado como sinônimo de violência doméstica em função da maior incidência deste tipo de violência ocorrer no espaço doméstico e/ou familiar.

Com o desenvolvimento dos estudos de gênero, a partir de 1990, alguns estudiosos passaram a utilizar o termo violência de gênero como um conceito mais amplo que violência contra a mulher (SAFFIOTI; ALMEIDA,1995). A violência de gênero não diz respeito apenas a violência perpetrada pelo homem contra a mulher, mas também a violência praticada pela mulher contra o homem, a violência entre mulheres e a violência entre homens (ARAÚJO; MARTINS; SANTOS, 2004).

Desse modo, pode-se afirmar que a violência contra a mulher é uma das principais formas de violência de gênero, ou seja, "a que incide, abrange e acontece sobre/com as pessoas em função do gênero ao qual pertence" (STREY, 2004, p. 13).

Verifica-se que devido à construção histórica da sociedade, as relações entre homens e mulheres são marcadas por condições de dominação masculina e submissão feminina. Neste sentido, a violência contra a mulher representa quase a totalidade da violência de gênero. Então, a opção pelo uso da denominação violência de gênero, implica a compreensão de que ela está fundamentada nas desigualdades entre homens e mulheres e, embora ela possa ser dirigida aos homens, a grande maioria dos casos ocorre no sentido inverso (SAFFIOTI; ALMEIDA, 1995).

A abordagem de gênero consolidou-se, de maneira progressiva, como modelo explicativo hegemônico para a ocorrência da violência contra a 


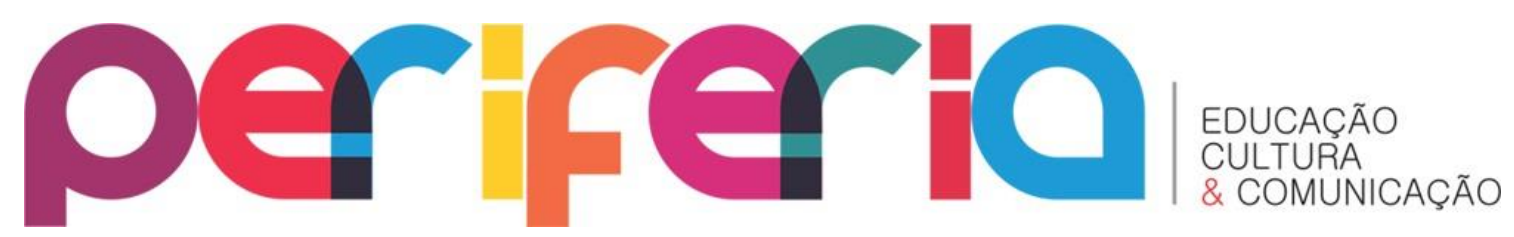

mulher. Dessa forma, a violência sofrida pela mulher é definida como uma violência ligada ao gênero, no qual as mulheres sofrem violência pelo fato de serem mulheres (SCHRAIBER et al., 2007).

Assim, a violência contra a mulher representa uma questão complexa, cujas origens encontram-se na organização social, nas estruturas econômicas e nas relações de poder, sendo necessária a implantação de políticas públicas voltadas para o respeito e a igualdade nas relações de gênero.

\section{O ENFRENTAMENTO À VIOLÊNCIA DE GÊNERO E POLÍTICAS PÚBLICAS}

Segundo Teles e Melo (2003) as políticas públicas representam um importante instrumento de transformação social e implementação da igualdade de gênero. Os autores afirmam que é preciso criar políticas de incentivo para o desenvolvimento de estratégias de reconhecimento da natureza complexa da violência contra a mulher, para alcançar uma abordagem integral do fenômeno na aplicação de medidas resolutivas.

De acordo com Bastos (2011) foi a partir década de 80 do século XX que as políticas públicas do ponto de vista do gênero começaram a ser implementadas no Brasil. Isso foi resultante das conferências internacionais sobre as mulheres e do movimento feminista. O Brasil é signatário de vários acordos internacionais que remetem, direta ou indiretamente, à questão da violência contra a mulher. Tais compromissos firmados pelo governo brasileiro perante a comunidade internacional criam consenso internacional sobre as matérias discutidas e definem objetivos, o que faz com que os países assumam a responsabilidade de implementar os princípios e programas aprovados pelas conferências como parte de suas políticas.

Em 10 de dezembro de 1948 a Organização das Nações Unidas (ONU) aprovou, em Paris, a Declaração Universal dos Direitos Humanos. Com esta Declaração, os direitos da pessoa humana passaram a ser incorporados ao patrimônio comum da humanidade e foram reconhecidos a nível internacional. Pela primeira vez passou-se a estabelecer as regras válidas 


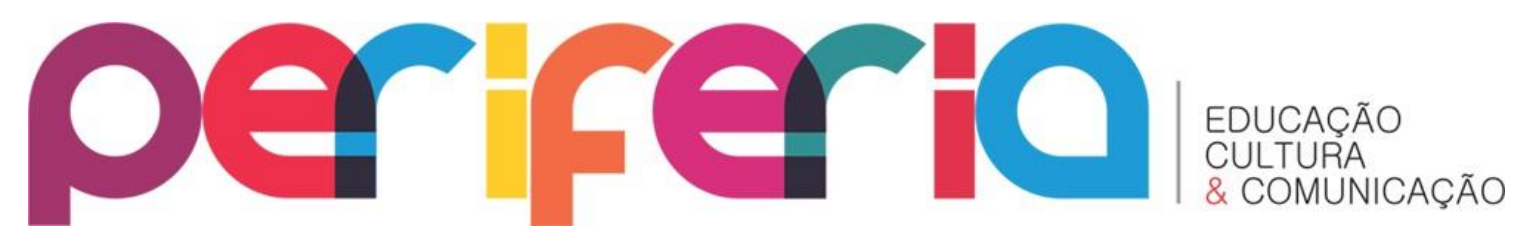

universalmente para todo o ser humano, independente de seu sexo, origem, raça, religião ou cultura. Conforme Bastos (2011, p. 39), esse documento internacional "transcendeu a noção genérica de soberania estatal e reconheceu a pessoa humana como sujeito de direitos universais".

$\mathrm{O}$ artigo $1^{\circ}$ da Declaração Universal dos Direitos Humanos dispõe que “todos os seres humanos nascem livres e iguais em dignidade e em direitos. Dotados de razão e de consciência, devem agir uns para com os outros em espírito e fraternidade" (ONU, 1948). Portanto, o ponto culminante da evolução dos direitos humanos foi este documento, no qual se pode afirmar que a igualdade entre os sexos foi positivada. Os direitos das mulheres passam a ser reconhecidos como direitos humanos e, como tal, merecedores da proteção estatal. Após a aprovação desta Declaração foram assinadas outras convenções em relação ao direito à igualdade de gênero, principalmente para combater a discriminação e a violência contra a mulher.

Segundo Moreira (2011) em 1979 foi realizada a Convenção das Nações Unidas sobre a Eliminação de Todas as Formas de Discriminação contra a Mulher, na qual definiu a discriminação contra a mulher como toda exclusão baseada no sexo que resulte em prejuízo ou anulação do exercício dos direitos humanos e liberdades fundamentais, no campo político, econômico, social, cultural, civil, dentre outros.

Essa convenção tratou ainda da violência contra a mulher, como qualquer conduta que provocasse algum prejuízo físico, além de ameaças de tais atos, a coerção ou a privação arbitrária da liberdade. Mas, foi apenas em 1993 durante a Conferência das Nações Unidas sobre Direitos Humanos, realizada em Viena, que ficou reconhecida formalmente a violência contra as mulheres como uma violação aos direitos humanos (MOREIRA, 2011).

A Convenção Interamericana para Prevenir, Punir e Erradicar a Violência Contra a Mulher realizada em Belém do Pará no ano de 1994 ampliou as considerações da Convenção de Viena, "consubstanciando-se em uma das principais conquistas dos movimentos feministas e influenciando novas 


\section{periferio}

políticas e estratégias de enfrentamento à violência de gênero" (BASTOS, 2011, p. 47).

Outro documento internacional importante na defesa dos direitos da mulher e no combate à violência foi a IV Conferência Mundial sobre as Mulheres realizada em 1995 na China onde foi identificada a violência contra a mulher como obstáculo ao alcance da igualdade e também como violação aos direitos humanos e às liberdades das mulheres (BASTOS, 2011).

Desse modo, a preocupação dos Estados diante da proteção dos direitos humanos é recente, surgindo precisamente após a Segunda Grande Guerra Mundial. Assim, a partir dos documentos internacionais em relação aos direitos fundamentais da pessoa humana, esses foram proclamados e inseridos de maneira explícita nas Constituições dos países (BASTOS, 2011).

Em 1985, quando se iniciou um processo de abertura política no Brasil, os movimentos de luta pela hegemonia nacional ressurgiram com o discurso de igualdade de direitos entre os vários grupos sociais. Neste contexto, foi promulgada a Constituição Federal de 1988 que instituiu um regime político democrático, além de proporcionar um grande avanço em relação aos direitos e garantias fundamentais (BRASIL, 1988).

A Constituição Federal de 1988 ficou conhecida como Constituição Cidadã, pois ao contrário do que se verificou nas Constituições anteriores. Esta se preocupou em estabelecer nos seus artigos iniciais os direitos fundamentais assegurados aos cidadãos brasileiros, visando a construção de uma sociedade mais justa e igualitária (BRASIL, 1988).

0 caput do artigo $5^{\circ}$ do referido texto constitucional determina que "todos são iguais perante a lei, sem distinção de qualquer natureza, garantindo aos brasileiros e aos estrangeiros residentes no país a inviolabilidade do direito à vida, à liberdade, à igualdade, à segurança e à propriedade". Em seguida, no inciso I, do mesmo artigo, dispõe que "homens e mulheres são iguais em direitos e obrigações" (BRASIL, 1988).

0 direito fundamental à igualdade entre homens e mulheres pressupõe, inicialmente, que a dignidade da pessoa humana pertence tanto ao gênero 


\section{periferio}

masculino, como ao gênero feminino. Assim, apesar das inúmeras diferenças biológicas e culturais, todos os seres humanos merecem igual respeito (COMPARATO, 2010).

A igualdade de gênero é parte crucial da garantia de maior representação da igualdade, pois "todos aqueles que possuem o status de cidadão no Estado-Nacional são iguais com respeito aos direitos e obrigações" (MARSHALL, 1967, p. 76). Portanto, a igualdade é fundamental para o exercício da cidadania. A cidadania é definida como o exercício pleno dos direitos políticos, civis e sociais, uma liberdade completa que combina igualdade e participação numa sociedade (CARVALHO, 2003).

Barsted (2007) afirma que na prática os direitos fundamentais não são acessíveis a todo e qualquer cidadão, em virtude principalmente da não observância da igualdade e da dignidade da pessoa humana. Neste sentido, o autor, apresenta a seguinte análise em relação à violação dos direitos da mulher:

No entanto, se os avanços legislativos são inquestionáveis, são também constantemente desafiados e tensionados pela drástica realidade de violação dos direitos humanos em escala planetária. Tanto no plano internacional quanto no Brasil, há um enorme fosso entre o reconhecimento da necessidade de formulação de políticas de promoção da igualdade de gênero, como dimensão constitutiva dos direitos humanos, e a implementação efetiva desses direitos (BARSTED, 2007, p. 119).

Rodrigues (2003) afirma que neste contexto, é imprescindível destacar também a influência do movimento feminista em relação à consolidação e efetivação dos direitos da mulher. 0 feminismo parte do reconhecimento da hierarquia social entre homens e mulheres, considerando-a historicamente determinada e injusta, e tem por finalidade eliminá-la. Assim, passa a reivindicar a igualdade de gênero e a consolidação da cidadania feminina.

Segundo Rodrigues (2003, p. 1), "a noção de cidadania alude não apenas à conquista de direitos, mas, sobretudo, a manutenção e ao 


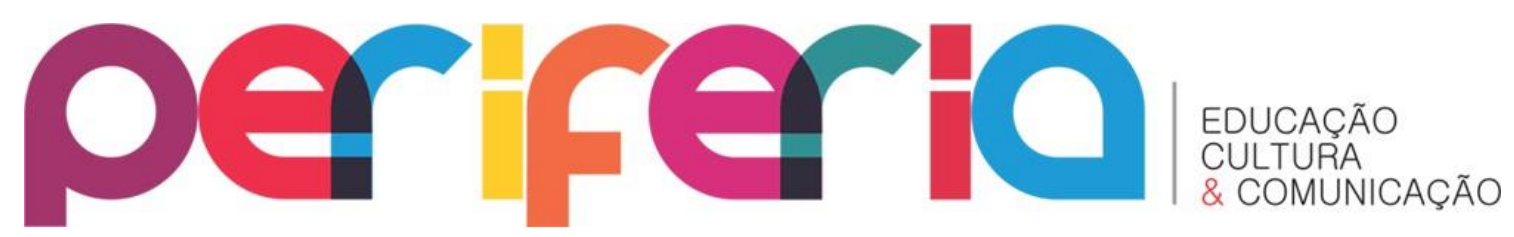

aprofundamento de direitos conquistados e acumulados historicamente". 0 autor enfatiza que o movimento feminista está inserido no processo de construção da cidadania. A busca pela cidadania das mulheres e a igualdade de gênero é um processo complexo e árduo.

No Brasil, a partir dos anos 70 do século XX o movimento feminista passou a denunciar os casos sobre a violência doméstica e familiar contra mulheres passando a exigir políticas públicas de enfrentamento a este tipo de violência. 0 movimento de mulheres, comparativamente a outros movimentos sociais, tem sido um dos movimentos que conseguiu resultados mais frutíferos no campo das políticas públicas, em decorrência, principalmente da dimensão propositiva do movimento e da sua disposição para uma interlocução com o Estado (RODRIGUES, 2003).

Implementar políticas públicas referentes ao gênero implica em desafios relacionados a vencer resistências internalizadas. Essas políticas representam instrumentos que o Estado possui, voltadas para superar ou ao menos amenizar as desigualdades, defender os direitos humanos, na sua integralidade, e atentar para as especificidades do sexo feminino (OLIVEIRA; CAVALCANTI, 2007).

Suárez e Bandeira (2002) afirmam que diante da complexidade que envolve a violência é necessária uma política que envolva as diversas esferas do poder público em conjunto com entidades da sociedade civil. É preciso ainda uma política social que vise superar o caráter descontínuo que tem caracterizado as políticas públicas no Brasil.

Segundo Rodrigues (2003) a implementação de políticas públicas é indispensável para a construção da cidadania das mulheres e a igualdade nas relações de gênero. A primeira experiência de implantação de uma política pública de combate à violência contra as mulheres no Brasil ocorreu em 1985 com a criação da Delegacia Especializada de Atendimento à Mulher-DEAM. No mesmo ano foi constituído o Conselho Nacional dos Direitos da Mulher. Em 1986, foi criada a primeira Casa-Abrigo para mulheres em situação de risco de morte do país. Essas três importantes conquistas da luta do movimento 


\section{periferio}

feminista no Brasil foram, durante muito tempo, as principais ações do Estado voltadas para a promoção dos direitos das mulheres no enfrentamento à violência.

Segundo Pasinato e Santos (2008) no ano de 2003 inaugurou-se uma nova fase nas políticas públicas de âmbito nacional relacionadas às mulheres, com a criação da Secretaria Especial de Políticas para as Mulheres, a qual recebeu o status de ministério, com orçamento próprio, poderes e autonomia administrativa para criar e executar políticas públicas voltadas para a ampliação e a garantia dos direitos das mulheres. Assim, a política de enfrentamento à violência contra as mulheres foi ampliada no sentido de promover a implantação de novos serviços e de propor a construção de Redes de Atendimento às mulheres em situação de violência.

Pasinato e Santos (2008) afirmam que com a realização da I e da II Conferência Nacional de Políticas para Mulheres e com a construção coletiva de dois Planos Nacionais de Políticas para Mulheres (2004 e 2008), o Enfrentamento à Violência contra as Mulheres é consolidado como um eixo intersetorial e prioritário no campo das políticas para as mulheres. Desta forma, as ações de enfrentamento à violência contra as mulheres não mais se restringem às áreas da segurança e assistência social, mas buscam envolver diferentes setores do Estado.

Em ambos os Planos Nacionais de Políticas para Mulheres, foi dedicado um capítulo específico sobre o enfrentamento à violência contra as mulheres que estabeleceu conceitos, princípios, diretrizes e ações de prevenção e combate à violência de gênero, assim como de assistência e garantia de direitos às mulheres em situação de violência. Foi utilizado um novo paradigma fundamentado nas concepções de rede e de transversalidade de gênero, articuladas em dois eixos. 0 primeiro eixo chamado horizontal afirma que os serviços devem fazer parte de uma rede intersetorial que possibilite $o$ atendimento integral às mulheres. O segundo eixo chamado de vertical estabelece que as políticas e serviços do Município, do Estado e da União devem estar articulados de forma a otimizar os recursos existentes e 


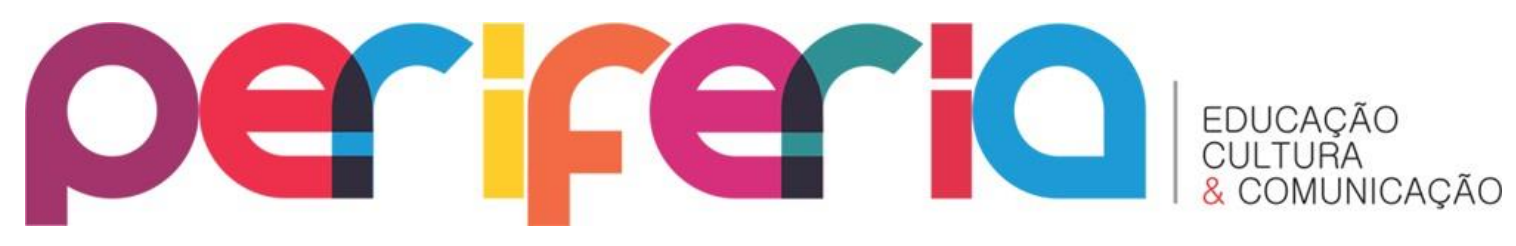

potencializar os resultados que possam ser alcançados (PASINATO; SANTOS, 2008).

A Rede de Enfrentamento à violência contra as mulheres tem por objetivo desenvolver estratégias efetivas de prevenção e de políticas que possam garantir o empoderamento das mulheres e seus direitos humanos, a responsabilização dos agressores e a assistência qualificada às mulheres em situação de violência. Desse modo, a Rede de Enfrentamento pretende efetivar os quatro eixos previstos na Política Nacional de Enfrentamento à Violência contra as Mulheres (combate, prevenção, assistência e garantia de direitos) e dar conta da complexidade do fenômeno da violência contra as mulheres (BRASIL, 2011).

Para atender esses objetivos, a Rede de Enfrentamento é integrada por agentes governamentais e não-governamentais que formulam, fiscalizam e executam políticas voltadas para as mulheres. Fazem parte organismos de políticas para as mulheres, ONGs feministas, movimento de mulheres, conselhos dos direitos das mulheres, outros conselhos de controle social e núcleos de enfrentamento ao tráfico de mulheres; serviços/programas que tratam da responsabilização dos agressores; universidades; órgãos federais, estaduais e municipais responsáveis pela garantia de direitos (habitação, educação, trabalho, seguridade social, cultura) e serviços especializados e não-especializados de atendimento às mulheres em situação de violência (BRASIL, 2011).

$\mathrm{Na}$ Rede de Enfrentamento encontram-se os serviços não-especializados e especializados de atendimento à mulher. Os serviços não-especializados de atendimento à mulher, na maior parte dos casos, constituem a porta de entrada da mulher na rede, são eles: hospitais gerais, serviços de atenção básica, programa saúde da família, delegacias comuns, polícia militar, polícia federal, Centros de Referência de Assistência Social, Centros de Referência Especializados de Assistência Social, Promotorias e Defensorias Públicas (BRASIL, 2011). 


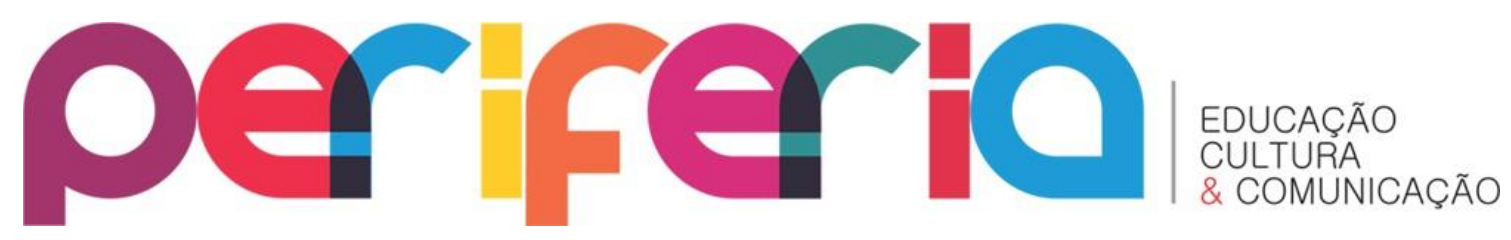

Já os serviços especializados de atendimento à mulher são aqueles que atendem exclusivamente a mulheres, como: Centros de Atendimento à Mulher em situação de violência, Casas Abrigo, Delegacias Especializadas de Atendimento à Mulher, Núcleos da Mulher nas Defensorias Públicas, Promotorias Especializadas, Juizados Especiais de Violência Doméstica e Familiar contra a Mulher, Central de Atendimento à Mulher, Ouvidoria da Mulher e serviços de saúde voltados para o atendimento aos casos de violência sexual e doméstica (BRASIL, 2011).

Portanto, a Rede de Enfrentamento à violência contra as mulheres leva em consideração a multiplicidade de serviços e de instituiçõos. Esta diversidade deve ser compreendida como parte de um processo de construção que visa abarcar a multidimensionalidade e a complexidade da violência contra as mulheres. No entanto, para que o enfrentamento da violência tornese efetivo, é importante que serviços e instituições possam atuar de forma articulada e integrada.

\section{CONSIDERAÇÕES FINAIS}

Conclui-se que a violência de gênero surge em decorrência do sistema de dominação inserido na sociedade, que utiliza desse mecanismo para manutenção da ordem estabelecida culturalmente, no qual posiciona a mulher numa posição inferior ao homem. Esta situação representa uma violação aos direitos humanos, ao direito à igualdade entre homens e mulheres. A mulher em situação de violência encontra-se numa relação onde a submissão ao homem é predominante, na qual há prejuízo a sua integridade física, psicológica e moral.

Foi a partir das conferências internacionais sobre a mulher e as lutas do movimento feminista que a questão da violência de gênero passou a ser considerada como um problema social, passando a requerer da sociedade e do Estado um entendimento mais amplo acerca da complexidade da questão. 


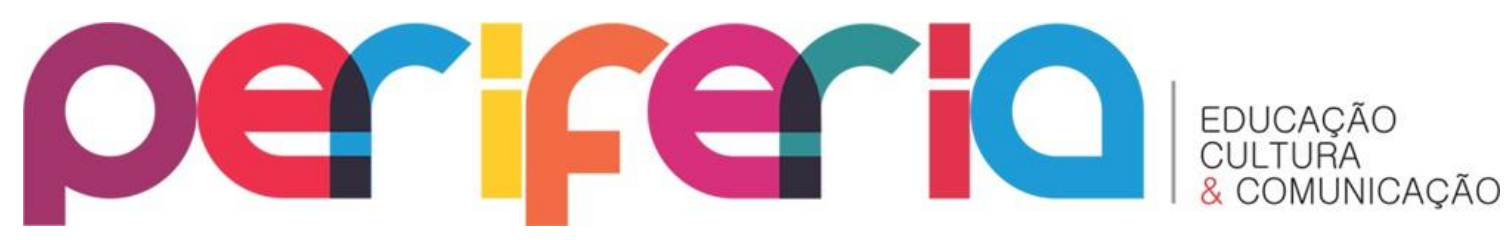

Desse modo, diante da violência contra mulher as políticas públicas tornaram-se necessárias no sentido de respeitar a igualdade nas relações de gênero e consolidar a cidadania feminina, com ações que assegurem um espaço de denúncia, proteção e apoio à mulher vítima de violência. A atuação deve ser em conjunta para o enfrentamento, prevenção, combate, assistência e garantia de direitos do problema pelas diversas esferas envolvidas, como: saúde, educação, assistência social, segurança pública, cultura, justiça, para dar conta da complexidade da violência contra as mulheres.

É necessário que órgãos componentes da Rede de Atendimento atuem de forma articulada de forma a garantir a integralidade da assistência à mulher. É fundamental também que os agentes que compõem essa Rede de Enfrentamento sejam devidamente capacitados na área de violência contra a mulher, principalmente nas questões de gênero, para compreender melhor o fenômeno e, assim, prestar um melhor atendimento às vítimas.

Desse modo, a Rede de Enfrentamento à violência de gênero será capaz de desempenhar um papel importante na política nacional de combate à violência de gênero, constituindo numa resposta eficaz a este tipo de violência, o que contribui diretamente na consolidação da cidadania feminina e colabora na construção de uma sociedade brasileira mais justa, na qual homens e mulheres são iguais e a violência contra a mulher é tratada com seriedade e devidamente reprimida.

\section{REFERÊNCIAS}

ARAÚJO, M. F. Gênero e violência contra a mulher: o perigoso jogo de poder e dominação. Psicologia para América Latina, México, n. 14, out. 2008.

ARAÚJO, M.F; MARTINS, E.J.S. \& SANTOS, A L. Violência de Gênero e Violência Contra a Mulher. In: Araújo, M.F. \& Mattioli, (orgs.) Gênero e Violência (p.1735). São Paulo: Arte \& \&Ciência, 2004.

BARSTED, L. L. A resposta legislativa à violência contra mulheres no Brasil. In: Almeida, S. S. (Org.). Violência de gênero e políticas públicas. Rio de Janeiro: Editora UFRJ, 2007. p. 119-137. 


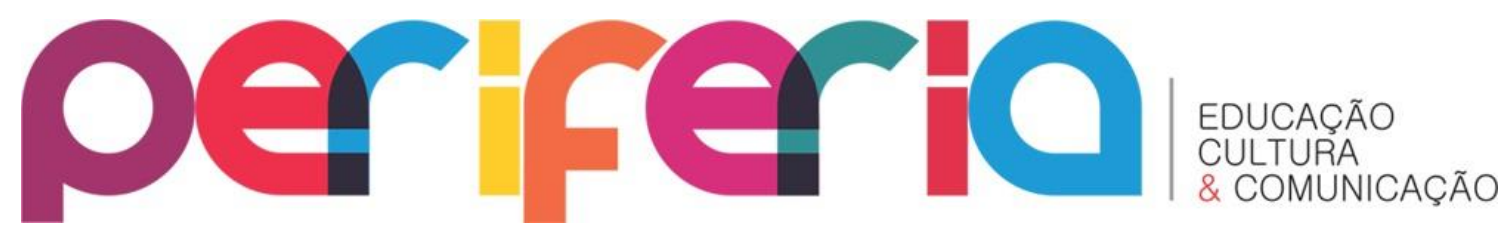

BASTOS, T. B. Violência doméstica e familiar contra a mulher: análise da Lei Maria da Penha. Porto Alegre: Ed. Verbo Jurídico, 2011.

BEAUVOIR, S. O segundo sexo: a experiência vivida. Tradução Sérgio Milliet. Rio de Janeiro: Nova Fronteira, 1980.

BRASIL. Constituição da República Federativa do Brasil. Brasília, DF: Senado, 1998.

- Rede de Enfrentamento à Violência contra as Mulheres. Brasília: Secretaria de Políticas para as Mulheres. 2011.

CARVALHO, J. M. Cidadania no Brasil: o longo caminho. Rio de Janeiro: Civilização Brasileira, 2003.

COMPARATO, F. K. A afirmação histórica dos direitos humanos. São Paulo: Saraiva, 2010.

DAY, V. P.; TELLES, L. E. B.; ZORATTO, P. H.; AZAMBUJA, M. R. F.; MACHADO, D. A.; SILVEIRA, M. B. Violência doméstica e suas diferentes manifestações. Revista de Psiquiatria do Rio Grande do Sul, v. 25, n. 1, p. 9-21, 2003.

FONTANA, M.; SANTOS, S. F. Violência contra a mulher. In: BRASIL, Rede Nacional Feminista de Saúde e Direitos Reprodutivos. Saúde da mulher $e$ direitos reprodutivos: dossiês. São Paulo, 2001. p. 101-128.

FOUCAULT, Michel. Microfísica do poder. Rio de Janeiro: Graal, 1979.

. História da sexualidade, Volume 1: A Vontade de saber. Rio de Janeiro: Graal, 2001.

GROSSI, M. P. Feministas históricas e novas feministas no Brasil. Antropologia em primeira mão. Florianópolis: PPGAS, n. 28, p. 284-307, 1998.

KOSS, M. V. Feminino + masculino: uma nova coreografia para a eterna dança das polaridades. São Paulo: Escrituras, 2000.

LAMOGLIA, C. V. A.; MINAYO, M. C. de S. Violência conjugal, um problema social e de saúde pública: estudo em uma delegacia do interior do Estado do Rio de Janeiro. Revista Ciência \& Saúde Coletiva. Vol. 14, № 2 (2009), p. 595604. ISSN 1413-8123.

LISBOA, M.; BARROSO, Z.; PATRÍCIO, J.; LEANDRO, A. Violência e género. Inquérito nacional sobre a violência doméstica exercida contra mulheres $e$ homens. Lisboa. Comissão para a Cidadania e Igualdade de Género, Colecção estudos de gênero, 2009. 


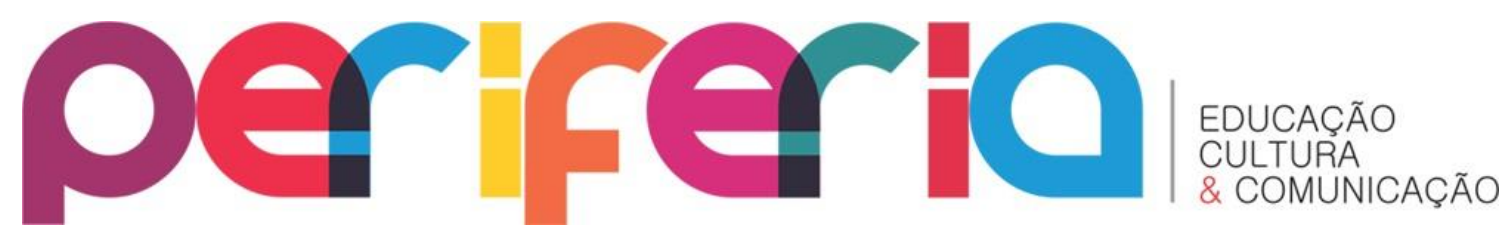

MARSHALL, T. H. Cidadania e classe social. Rio de Janeiro: Zahar, 1967.

MOREIRA, M. Violência doméstica e familiar: a lei Maria da Penha e o princípio da igualdade e a dignidade da pessoa humana. Porto Alegre: Nuria Fabris Editora, 2011.

MORGADO, R. Mulheres em situação de violência doméstica: Limites e possibilidades de enfrentamento. In: SIGNORINI H.; BRANDÃO E. (Orgs.). Psicologia jurídica no Brasil. Rio de Janeiro, Nau, 2004. p. 309-339.

OLIVEIRA, A. P. G, CAVALCANTI, V. R. S. Violência Doméstica na Perspectiva de gênero e Políticas Públicas. Rev. Brás. Crescimento Desenvolvimento Humano, 2007.

ORGANIZAÇÃO DAS NAÇÕES UNIDAS-ONU. Declaração universal dos direitos humanos. Paris, 1948.

ORGANIZAÇÃO DOS ESTADOS AMERICANOS-OEA. Convenção Interamericana para prevenir, punir e erradicar a violência contra a mulher. Belém-PA, 1994.

PASINATO, W.; SANTOS, C. M. Mapeamento das delegacias da mulher no Brasil. Campinas: Núcleo de Estudos de Gênero - Pagu/Unicamp, 2008.

ROGRIGUES, A. Construindo a perspectiva de gênero na legislação e nas políticas públicas. 2003.2 Disponível em: <http://www.maismulheresnopoderbrasil. com.br/estudos. php> Acesso em: 15 maio 2017.

SCOTT, J. Gênero: uma categoria útil de análise histórica. Educação $e$ Realidade. Porto Alegre, v.16, $\mathrm{n}^{\circ} 2$, jul/dez 1990.

SAFFIOTI, H. I. B. Violência de gênero no Brasil contemporâneo. In: SAFFIOTTI, Heleieth I. B.; MUÑOZ-VARGAS, M. (Orgs.). Mulher brasileira é assim. Rio de Janeiro: Rosa dos Tempos-NIPAS/UNICEF, 1994. p. 151-187.

Abramo, 2004.

Gênero, patriarcado, violência. São Paulo: Editora Fundação Perseu

SAFFIOTI H. I. B.; ALMEIDA S. S. Brasil: violência, poder, impunidade. In: SAFFIOTI H. I. B.; ALMEIDA S. S. Violência de gênero: poder e impotência. Rio de Janeiro: Ed. Revinter, 1995, p. 3-27.

SAGOT, M. A rota crítica da violência intrafamiliar em países latinoamericanos. In MENEGHEL, S. N. (Org.). Rotas críticas: mulheres enfrentando a violência. São Leopoldo: Editora Unisinos, 2007, p. 23-50. 


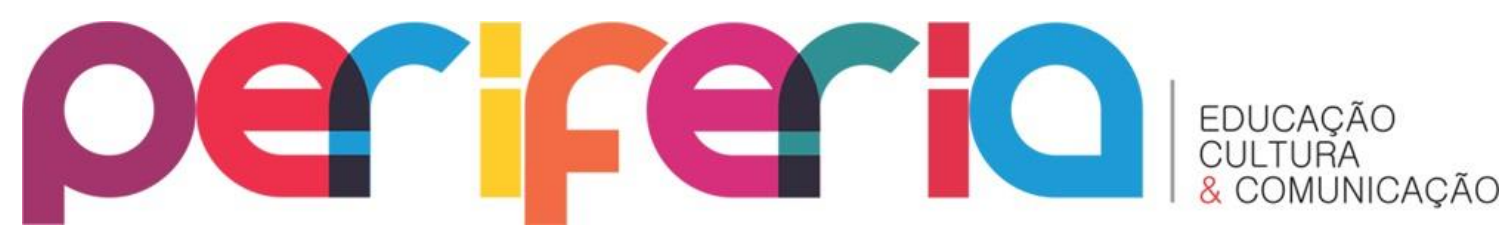

SCHRAIBER, L. B., D'OLIVEIRA, A.; COUTO, M. T.; HANADA, H.; KISS, L. B.; DURAND, J. G. Violência contra mulheres entre usuárias de serviços públicos de saúde da Grande São Paulo. Revista de Saúde Pública, v. 41, n. 3, p. 359367, 2007.

STREY, M. N. Violência de gênero: uma questão complexa e interminável. In: STREY, M. N; AZAMBUJA, M. P. R.; JAEGER, F. P. (Orgs.). Violência, gênero e políticas públicas. Porto Alegre: EDIPUCRS, 2004. p. 13-43.

SUÁREZ, M.; BANDEIRA, L. A politização da violência contra a mulher e o fortalecimento da cidadania. In: BRUSCHINI, C.; UNBEHAUM, S. (Orgs.). Gênero, democracia e sociedade brasileira. São Paulo: Fundação Carlos Chagas, 2002. p. 307-309.

TAVARES, M. S.; SARDENBERG, C. M. B.; GOMES, M. Q. Feminismo, estado e políticas de enfrentamento à violência contra mulheres: monitorando a lei Maria da Penha. Labrys Estudos Feministas. Florianópolis: UFSC, jun./dez. 2011.

TELES, M. A. de A.; MELO, M. de. $O$ que é violência contra a mulher. São Paulo: Brasiliense, 2003. 